\title{
PENGARUH EXPERIENTIAL MARKETING TERHADAP MINAT BELI PRODUK UMKM BERBAHAN TALAS DI KOTA BOGOR
}

\section{THE INFLUENCE OF EXPERIENTIAL MARKETING ON THE BUYING INTEREST OF UMKM PRODUCTS MADE FROM TARO IN BOGOR CITY}

\author{
Ahmad Jaenal Awaludin ${ }^{1)}$; Titiek Tjahja Andari' ${ }^{2}$ \\ Program Studi Manajemen Fakultas Ekonomi Universitas Djuanda Bogor \\ Email: ahmadajaenalawaludinilmu@gmail.com
}

\begin{abstract}
The purpose of this research was to know the impact of experiential marketing to the buying interest of UMKM products made of taro in Bogor. The study sampel was 100 respondens by purposive sampling. This research is categorized as descriptive research associative and analysis tool used is multiple regression. Based on the result of this research indicate that simultaneously sense, feel, think, act and relate have a positive effect on buying interest. The impact of highest variabel resulting the act variabel, while the lowest is the feel variable. By using t-test, found that feel, think, act and relate have a significant influence while sense was not significant
\end{abstract}

Keywords: Experiential Marketing, sense, feel, act, relate and buying interest.

\begin{abstract}
ABSTRAK
Tujuan dari penelitian yaitu untuk mengetahui pengaruh secara simultan dan parsial experiental Marketing terhadap minat membeli produk berbahan talas di Bogor. Sampel penelitian berjumlah 100 responden yang ditentukan secara purposive sampling. Penelitian ini merupakan penelitian deskriptif asosiatif dan alat analisis menggunakan regresi berganda. Temuan penelitian menunjukkan bahwa secara simultan sense, feel, think, act dan relate memberikan pengaruh positif terhadap minat beli. Pengaruh variabel tertinggi adalah variabel act, sedangkan yang terendah adalah variabel feel. Uji signifikansi dengan uji-t menunjukkan feel, think, act dan relate mempunyai pengaruh yang signifikan terhadap minat beli sedangkan sense tidak berpengaruh signifikan.

Kata kunci : Experiential marketing, sense, feel, think, act, relate dan minat beli.
\end{abstract}




\section{PENDAHULUAN}

Keberhasilan sebuah usaha tergantung dari pelaku usaha dalam hal menyikapi pangsa pasar dan melakukan strategi dalam mempengaruhi calon pembeli agar berminat untuk membeli produk yang ditawarkan. Pelaku usaha harus memiliki strategi yang efektif dan tepat agar produk yang ditawarkan dapat mempengaruhi calon konsumen dan dapat diterima di masyarakat.

Salah satu dari strategi pemasaran yang dapat dilakukan adalah experiential marketing. Experiential marketing merupakan salah satu strategi yang memperlakukan pembeli dengan cara memperhatikan dan memadukan antara emosi, logika, dan proses berpikir agar memberikan pengalaman positif. Salah satu cara mempengaruhi minat beli dari konsumen adalah ketika pelaku usaha dapat memberikan suatu kesan yang sangat baik terhadap konsumen. Tujuan experiential marketing yaitu memberikan suatu pengalaman positif kepada konsumen agar terpikat terhadap segala sesuatu yang ditawarkan melalui sense (panca indra), feel (perasaan), think (pikiran), act (tindakan) dan relate (pertalian)

Menurut Kotler (2012) minat beli merupakan suatu perilaku konsumen yang akan muncul sebagai tanggapan/respon terhadap objek tertentu sebagai bentuk keinginan dari pelanggan untuk melakukan pembelian.

Minat adalah suatu keinginan yang diutarakan melalui rasa ingin memiliki suatu hal. Jadi inilah yang akan dimanfaatkan oleh pelaku usaha terhadap pembeli sehingga pembeli memiliki suatu keinginan untuk memiliki produk yang ditawarkan melalui rasa ingin memiliki.

Bogor adalah kota yang memiliki komoditas produk UMKM (Usaha Mikro Kecil Menengah) yang berupa jasa, perdagangan, tektil, makanan minuman dan industri yang dapat dikembangkan, dari beberapa jenis komoditas tersebut menurut data UMKM kota Bogor dapat dilihat pada tabel 1 berikut :

Tabel 1. Persentase UMKM Kota

Bogor Tahun 2015

\begin{tabular}{|c|c|c|c|}
\hline $\mathrm{No}$ & Konoditas & In miah UTEMI & Persetase $(2)$ \\
\hline 1. & Jaa & 2319 & 15 \\
\hline 2 & Perdagaga & 5.410 & 35 \\
\hline 3. & Telotel & 1855 & 12 \\
\hline 4 & Makcnen den nomman & 4328 & 28 \\
\hline & Intustri & 1.546 & 10 \\
\hline \multicolumn{2}{|c|}{ Intiah } & 15.458 & 100 \\
\hline
\end{tabular}

Sumber: Dinas Koperasi dan UMKM Kota Bogor , 2016 (Diolah).

Tabel 1 menunjukkan bahwa UMKM yang terbanyak dibidang perdagangan sebanyak $35 \%$ dan diikuti oleh makananminuman sebanyak $28 \%$, artinya potensi berkembangnya makanan dan minuman cukup tinggi. Banyaknya komoditas UMKM dibidang makanan dan minuman dapat dilihat pada tabel 2 berikut :

Tabel 2. Persentase UMKM Makanan-

Minuman Kota Bogor Tahun 2015

\begin{tabular}{llcc}
\hline No & Komoditas & Jumlah UMKM & Persentase (\%) \\
\hline 1. & Makanan Ringan & 1.310 & 30,27 \\
2. & Masakan & 618 & 14,28 \\
3. & Kue kering dan Basah & 594 & 13,72 \\
4. & Makanan Berkuah & 521 & 12,04 \\
5. Gorengan & 472 & 10,91 \\
6. Minuman & 420 & 9,70 \\
7. Makanan Berat & 352 & 8,13 \\
8. Rujak & 29 & 0,67 \\
9. Manisan & 12 & 0,28 \\
\hline Jumlah & 4.328 & 100 \\
\hline
\end{tabular}

Sumber : Dinas Koperasi dan UMKM Bogor, 2016 (Diolah)

Tabel 2 memperlihatkan bahwa komoditas kue kering dan basah berada diurutan ke-3 sebanyak $13,72 \%$ dan dari komoditas kue kering dan basah tersebut $4,38 \%$ merupakan produk makanan berbahan talas. Produk berbahan talas merupakan produk unggulan daerah kota Bogor, dikarenakan talas merupakan icon atau ciri khas Bogor. Proporsi UMKM produk berbahan talas masih tergolong rendah. Rendahnya produk berbahan dasar talas disebabkan oleh persaingan dalam melakukan penjualan dengan produk lain, maka perlu dipelajari dan diuji strategi yang dapat mendorong minat beli produk berbahan talas agar jumlah UMKM meningkat, di antaranya dengan 
mengembangkan strategi experiential marketing.

\section{MATERI DAN METODE}

Untuk membangun hubungan dengan pelanggan diperlukan suatu strategi yang dapat menciptakan kesadaran pelanggan tentang barang dan jasa. Dalam memilih stategi pemasaran terdapat berbagai macam strategi yang dapat digunakan, dan tentunya strategi tersebut harus sesuai dengan kondisi pasar dan produk yang ingin di tawarkan ke pasar. Di antara strategi yang dapat digunakan yaitu: turbo marketing, mega marketing, SWOT, Experiential marketing, relationship marketing, customer loyalty dll. Dalam hal ini penyaji ingin menguji strategi experiential marketing dikarenakan konsumen pada saat ini tidak hanya mementingkan produk saja, tetapi ada harapan lebih mengenai produk yang dibelinya .

\section{Experiential Marketing}

Experiential Marketing merupakan salah satu strategi pemasaran untuk mempengaruhi minat beli dengan cara memperlakukan konsumen melalui perpaduan antara sense, feel, think, Act dan relate, sehingga memberikan suatu pengalaman positif terhadap konsumen. Tahapan keberhasilan dari suatu strategi experiential marketing yaitu melalui sense, feel, think, act dan relate. Menurut Schmitt bahwa merek-merek dapat menciptakan 5 tahap pengalaman yang berbeda yaitu; mengindra, merasa, berpikir, bertindak dan berelasi.

Menurut Alma (2014) strategi experiential marketing konsumen tidak saja melakukan permintaan barang berkualitas, tapi juga menginginkan ada manfaat emosional, berupa memorable experience yaitu adanya pengalaman yang mengesankan tidak terlupakan, pengalaman unik yang positif, pengalaman holistic melalui seluruh panca indranya.

Tujuan dari strategi experiential marketing adalah konsumen memiliki pengalaman yang positif sehingga terpikat dengan produk yang ditawarkan.

\section{Indikator Experiential Marketing}

1. Sense

Menurut Alma (2014) melalui sense akan tercipta sensory experiences yang dapat memberikan kesan keindahan, kesenangan, kepuasan. Dalam hal menciptakan sense terhadap suatu produk harus mencakup penglihatan (desain produk), suara (dibicarakan), sentuhan (produk lembut), perasaan (varian rasa), kualitas (cita rasa), dan penciuman (aroma)

2. Feel.

Feel ini menyentuh inner feelings dan emotions, dengan sasaran membangkitkan pengalaman efektif, sehingga ada rasa gembira dan bangga. Di sini harus dipertimbangkan mood dan emotion pelanggan. Mood diperoleh dengan rangsangan khusus, akan tetapi pelanggan tidak menyadari akan hal tersebut. Sedangkan emotion diupayakan dengan sengaja oleh pemasar, misalnya tumbuh rasa cinta. Demikian pula emosi, ada basic emotion, seperti rasa gembira, marah, dan ada complex emotion, seperti munculnya rasa nostalgia

Menurut Alma (2014) feel akan menyentuh inner feelings and emotions, dengan sasaran membangkitkan pengalaman efektif, sehingga ada rasa gembira dan bangga. Berdasarkan pengertian tersebut, kesan feel terhadap produk harus mencakup; 1) suasana hati yaitu kondisi positif dan negative menentukan produk apa yang akan dibeli konsumen, sehingga pelaku usaha harus memiliki dampak positif yang akan selalu diingat oleh konsumen) : 2) emosi yaitu rasa yang lebih kompleks dari suasana hati seperti iri, marah, cinta dll.

3. Think.

Menurut Alma (2014) bahwa think akan menciptakan aspek kognitif, problem-solving experiences. Think akan muncul dalam suatu pemikiran yang 
divergen dan convergent. Pikiran yang bagus akan mampu berpikir secara positif, sehingga dapat memberikan opini positif terhadap produk dan lembaga.

Menurut Kertajaya (2006) Think marketing adalah cara yang dilakukan perusahaan agar komoditas menjadi suatu pengalaman (experience) dengan melakukan customization secara terusmenerus. Agar tujuan mempengaruhi pemikiran calon konsumen dapat tercapai terdapat beberapa hal yang harus dilakukan yaitu ;1) Memberikan surprise (kejutan) ;2) intrique (memikat) dengan cara mengetahui secara mendalam tentang konsumen sasaran mengenai apa saja keinginan dan harapannya terhadap produk perusahaan; 3) provocation (provokasi) yang sering disebut dengan propaganda yang dapat dilakukan melalui event indoor maupun outdoor dengan menggunakan media cetak mau visual televisi dan internet

4. Act.

Act akan menyentuh pengalaman dalam gaya dan berinteraksi dengan perubahan gaya hidup, dilakukan secara spontan karena dapat melihat model, dan konsumen akan melakukan pembelian karena adanya pengaruh yang berasal dari luar dan opini dari dalam dirinya.

Menurut Kertajaya (2006) act Marketing adalah suatu cara untuk membentuk persepsi pelanggan terhadap barang dan jasa bersangkutan. Maka perlu diperhatikan keunikan, menarik, terkenal, mudah didapatkan, harga sesuai dengan manfaat yang dijanjikan.

5. Relate.

Menurut Alma (2014) relate adalah suatu pengalaman individu untuk berhubungan dengan individu yang lain dalam budaya tertentu. Sedangkan menurut Kertajaya (2006) relate marketing adalah suatu cara untuk membentuk dan menciptakan suatu komunitas diantara pelanggan melalui komunikasi.

\section{Minat Beli}

Minat beli merupakan rasa ingin memiliki sesuatu dengan tidak disadari atau tanpa adanya suatu rangsangan atau stimulus. Minat merupakan sesuatu yang ingin diutarakan melalui rasa ingin memiliki sesuatu hal. Jadi ini lah yang ingin dimanfaatkan secara optimal oleh pelaku usaha sehingga konsumen memiliki rasa ingin memiliki produk yang akan ditawarkan melalui rangsangan fisiologi terhadap konsumen.

Menurut Kotler (2012) minat beli merupakan perilaku yang akan muncul sebagai tanggapan atau respon terhadap objek yang menunjukkan adanya keinginan dari konsumen untuk melakukan pembelian.

\section{Indikator Minat Beli}

Menurut Schiffman dan Kanuk (2007) terdapat tiga komponen yang dapat mempengaruhi sikap konsumen terhadap minat untuk membeli yaitu:

1. Komponen kognitif (kognisi), yaitu suatu pengetahuan dan keyakinan (persepsi) yang diperoleh konsumen melalui kombinasi informasi yang berkaitan dengan terkenalnya produk tersebut dan pengalamanan secara langsung terhadap penggunaan produk tersebut.

2. Komponen afektif, yaitu memfokuskan pada emosi atau perasaan konsumen yang sifatnya evaluative, menentukan nilai individu secara menyeluruh terhadap sikap dan kesediaan menerima yang mencakup periode peningkatan varian dan eksistensi produk.

3. Komponen konatif (konasi), yaitu kecenderungan berperilaku yang dilakukan oleh individu terhadap objek sikap tertentu seperti keuntungan membeli dan kerugian tidak membeli .

\section{Kerangka Berpikir}

Kerangka berpikir secara teoritis menjelaskan pertautan antar variabel sehingga dirumuskan dalam suatu kerangka penelitian dan membentuk skema seperti gambar di bawah ini : 


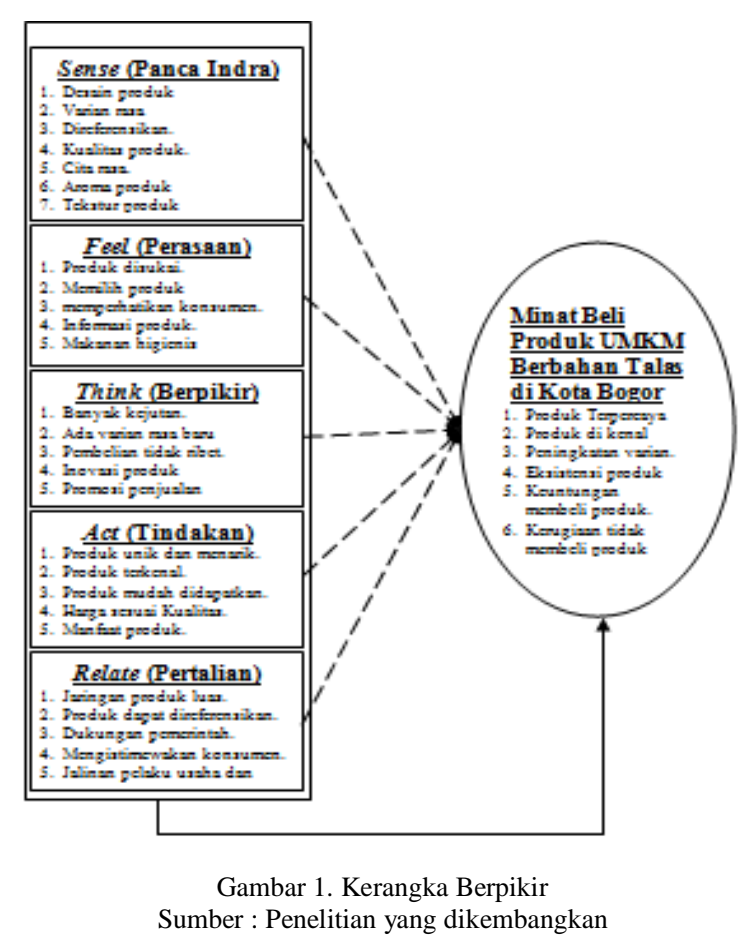

\section{Desain Penelitian}

Objek penelitian adalah produk UMKM berbahan dasar talas. Penelitian ini menggunakan pendekatan deskriptif yaitu untuk memperoleh gambaran data yang sudah terkumpul tanpa bermaksud untuk mengambil kesimpulan yang berlaku umum. Rumusan masalah menggunakan asosiatif kausal/sebab akibat yang sifatnya mempertanyakan hubungan antara dua variabel atau lebih. Dengan penelitian yang dilakukan diharapkan memperoleh informasi mengenai pengaruh dari experiential marketing terhadap minat beli produk UMKM berbahan dasar talas di Bogor.

Teknik pengumpulan data dilakukan dengan interview (wawancara), kuesioner dan obervasi. Data yang digunakan adalah data yang diperoleh dengan cara memberikan angket pertanyaan (kuesioner). Penilaian responden terhadap variabel yang diteliti menggunakan skala Likert.

\section{Sampel}

Untuk menentukan jumlah sampel menggunakan populasi semua masyarakat yang pernah membeli produk berbahan talas, sehingga populasi tidak diketahui
jumlahnya.Untuk menentukan jumlah sampel tanpa diketahui populasinya dapat menggunakan rumus Lemeshow (1997) dengan rumus yaitu :

$n=\frac{p(1-p)\left(z_{1-a / 2}\right)^{2}}{D^{2}}$

Keterangan:

$\mathrm{n}$ : Jumlah sampel

Z: Tingkat kepercayaan

P: Maksimal estimation (0.5)

D: Limit dari Error

Dengan menerapkan rumus diatas maka jumlah sampelnya adalah ;

$$
\begin{aligned}
\mathrm{n} & =\frac{0,5(1-0,5)(1,96)^{2}}{\left(0.1^{2}\right)} \\
& =96,04
\end{aligned}
$$

Berdasarkan perhitungan menggunakan rumus Lemeshow maka sampel penelitian dibulatkan berjumlah 100 responden.

\section{Teknik Pengambilan sampel}

Teknik sampling menggunakan nonprobability sampling dengan teknik purposive sampling (teknik penentuan sampel berdasarkan pertimbangan tertentu). Hal ini sebagai pertimbangannya ialah pernah membeli dan merasakan produk berbahan talas minimal dua kali melakukan pembelian.

\section{Variabel Penelitian}

Variabel independen (variabel yang mempengaruhi variabel $\mathrm{Y}$ ) adalah variabel $\mathrm{X}$ (experiential marketing), terdiri dari sub variabel $\mathrm{X}_{1}=$ sense (panca indra), $\mathrm{X}_{2}=$ feel (perasaan), $\mathrm{X}_{3}=$ think (berfikir), $\mathrm{X}_{4}=a c t$ (tindakan), $\mathrm{X}_{5}$ dan relate (pertalian), sedang kan variabel dependen (variabel yang dipengaruhi variabel $\mathrm{X}$ ) adalah variabel $\mathrm{Y}$ (minat beli)

\section{Metode Analisis Data}

Data dianalisis menggunakan analisis deskriptif yaitu untuk mengetahui gambaran karakteristik responden yang akan 
ditanyakan melalui koesiner, sehingga menghasilkan nilai frekuensi dan nilai ratarata (mean). Teknik yang digunakan untuk menganalisis data adalah regresi berganda, pengujian korelasi berganda, koefisien determinasi, koefisien korelasi, Uji $\mathrm{F}$ dan uji-t.

\section{Uji Asumsi Klasik}

Menurut Damodar Gujarati (2006) uji asumsi klsik dilakukan agar model regresi tidak BLUE ( best linier unbiased estimator) atau tidak bias, sehingga diperoleh gambaran hubungan antara variabel independen dan dependen secara parsial maupun simultan. Uji asumsi yang dilakukan adalah; 1) uji normalis yang dilakukan yaitu metode histogram, probability plots dan Kolmogorov-Smirnov, hasil pengujian normalitas semua data dinyatakan berdistrubusi normal ;2) Uji multikoliniaritas yang dilakukan dengan menggunakan VIF (Varians Inflation Factor.) Hasil pengujian tidak terjadi multikoliinieritas`; 3) Uji heteroskedanitas dilakukan dengan menggunakan scatter plot dan hasil menunjukkan titik-titik tersebar secara acak memberikan tanda tidak terjadi heterokedasitas.

\section{HASIL DAN PEMBAHASAN}

Deskripsi data berasal dari kuesioner yang disebarkan terhadap 100 responden. Karakteristik responden dibedakan berdasarkan jenis kelamin, umur, pekerjaan, status pernikahan, pendidikan dan pendapatan per bulan. Adapun gambaran umum responden produk berbahan talas berjenis kelamin perempuan adalah sebanyak $60 \%, 50 \%$, berumur antara 17-24 tahun, $45 \%$ responden adalah pekerja swasta, $66 \%$ responden berstatus menikah, 57\% responden pendidikan SMU, pendapatan responden perbulan antara Rp. $1.900 .000-$ 4.000.000 sebesar 56\%.
Berikut adalah tanggapan responden terhadap experiential marketing produk berbahan talas di Bogor :

Tabel 3. Rekapitulasi Tanggapan

Responden Pada Experiential Marketing.

\begin{tabular}{cccc}
\hline No & Variabel & Skor & Keterangan \\
\hline 1 & Sense & 3,88 & Tinggi \\
2 & Feel & 3,64 & Tinggi \\
3 & Think & 3,82 & Tinggi \\
4 & Act & 3,93 & Tinggi \\
5 & Relate & 3,92 & Tinggi \\
\hline
\end{tabular}

Sumber : Data kuesione,r, 2017 (Diolah)

Dari tabel 3 diatas terlihat bahwa sub variabel act dinilai reponden paling tinggi hal ini menunjukkan penyampaian stimulus berupa produk unik dan menarik, kesan high class, produk mudah didapatkan, harga sesuai kualitas dan manfaat bagi kesehatan akan memberikan tindakan yang nyata sehingga konsumen membeli produk perusahaan, sedangkan feel dinilai konsumen paling rendah sehingga menunjukkan penyampaian stimulus feel berupa produk disukai, melibatkan konsumen, variasi produk sesuai, informasi lengkap, dan produk higienis, informasi produk yang ingin disampaikan perusahaan dapat diterima oleh konsumen namun perlu ada peningkatan penyampaian agar mampu memikat konsumen.

Tabel 4. Rekapitulasi Tanggapan Responden Terhadap Minat Beli.

\begin{tabular}{|c|c|c|c|}
\hline Pertanyaan & Indikator & Nilai & Kriteria \\
\hline \multirow[t]{2}{*}{$\mathrm{Y}_{1}$} & Minat karena & 3,80 & Minat \\
\hline & Produk terpercaya & & \\
\hline $\mathrm{Y}_{2}$ & Produk dikenal. & 3,77 & Minat \\
\hline $\mathrm{Y}_{3}$ & $\begin{array}{l}\text { Minat karena } \\
\text { Produk bervarian. }\end{array}$ & 3,85 & Minat \\
\hline $\mathrm{Y}_{4}$ & $\begin{array}{l}\text { Minat karena } \\
\text { eksistensi produk. }\end{array}$ & 3,82 & Minat \\
\hline $\mathrm{Y}_{5}$ & $\begin{array}{ll}\text { Minat } & \text { karena } \\
\text { banyak } & \\
\text { keuntungan. } & \\
\end{array}$ & 3,61 & Minat \\
\hline \multirow[t]{3}{*}{$\mathrm{Y}_{6}$} & $\begin{array}{l}\text { Minat karena oleh- } \\
\text { oleh Bogor tidak } \\
\text { lengkap } \\
\text { produk talas. }\end{array}$ & 4,19 & Minat \\
\hline & TOTAL & 23,04 & \\
\hline & Rata-rata & 3,85 & Minat \\
\hline
\end{tabular}

Sumber : Data kuesioner, 2017 (Diolah)

Tabel 4 merupakan rekapitulasi rata-rata penilaian dari konsumen mengenai variabel Y (minat beli) sebesar 3,85 yang artinya konsumen berminat membeli produk berbahan talas. Dengan kriteria penilaian 
konsumen terhadap variabel $\mathrm{Y}$ (minat beli) dengan nilai tertinggi sebesar 4,19 berminat membeli produk perusahaan karena produk berbahan talas merupakan oleh-oleh khas Bogor sehingga tidak lengkap tanpa membeli produk talas, , sedangkan nilai terendah sebesar 3,61 berminat karena banyaknya keuntungan yang ditawarkan, dikarenakan produk berbahan talas memiliki banyak keuntungan baik secara kualitas dan harganya, namun perlu diinformasikan tentang manfaat kesehatan talas agar konsumen mengetahui manfaat lebih dari produk talas, seperti yang ditulis Emma (2007) manfaat talas bagi kesehatan diantaranya menghilangkan dahak, meningkatkan kerja ginjal, menghilangkan racun tubuh.

\section{Pengujian Regresi Berganda}

Regresi berganda dilakukan untuk mengetahui bagaimana keadaan variabel dependen (naik turunnya), bila terdapat dua atau lebih dari variabel independen sebagai faktor prediktor, sehingga dapat diketahui ada/tidaknya pengaruh dari variabel independen terhadap variabel dependen.

Tabel 5. Hasil Perhitungan Regresi

\begin{tabular}{|c|c|c|c|c|c|}
\hline \multicolumn{6}{|c|}{ Coefficients ${ }^{2}$} \\
\hline \multirow[b]{2}{*}{ Hodel } & \multicolumn{2}{|c|}{ Unstandardaed Coefficients } & \multirow{2}{*}{$\frac{\text { Sandardoed Coeficierts }}{\text { Beda }}$} & \multirow[b]{2}{*}{ t } & \multirow[b]{2}{*}{ Sig. } \\
\hline & 8 & Sid. Ertor & & & \\
\hline 1 (Constan) & 125 & 1,775 & & 070 & 344 \\
\hline Sense & 068 & .057 & 005 & 1011 & 314 \\
\hline Fes: & 200 & 100 & 78 & 2008 & 948 \\
\hline Think & 384 & .997 & 346 & 4669 & .000 \\
\hline Adt & 288 & 112 & 221 & 2664 & .009 \\
\hline Ralate & 206 & 103 & 105 & 2001 & 148 \\
\hline
\end{tabular}

Berdasarkan hasil perhitungan pada tabel 4 dapat disimpulkan persamaan regresi nya sebagai berikut:

$$
\begin{aligned}
Y & =0,125+0,068 X_{1}+0,200 X_{2}+0,394 X_{3} \\
& +0,298 X_{4}+0,206 X_{5}+\varepsilon
\end{aligned}
$$

Persamaan regresi berganda tersebut memberikan pengertian bahwa koefisien $\mathrm{X}_{1}$ dengan nilai positif 0,068 artinya bahwa semakin tinggi sense terhadap produk seperti desain, varian rasa, direferensikan dan dibicarakan, kualitas produk, cita rasa, aroma produk dan teksturnya yang bagus maka akan meningkatkan minat beli terhadap produk berbahan talas.

Koefisien $\mathrm{X}_{2}=0,200$ artinya semakin tinggi feel produk seperti produk disukai, melibatkan konsumen, variasi produk sesuai, informasi lengkap, dan produk higienis akan meningkatkan minat beli dari konsumen terhadap produk berbahan talas.

Koefisien $\mathrm{X}_{3}$ menunjukkan nilai positif sebesar 0,394 yang artinya bahwa semakin tinggi think terhadap produk dalam hal kejutan rasa, varian rasa baru, ciri khas, inovasi produk dan promosi menarik maka dapat meningkatkan minat beli terhadap produk berbahan talas.

Koefisien $\mathrm{X}_{4}=0,298$ artinya semakin tinggi act yang diberikan terhadap produk seperti rasa produk unik dan menarik, kesan high class, produk mudah didapatkan, harga sesuai kualitas dan manfaat bagi kesehatan maka minat beli produk berbahan talas akan terus meningkat.

Koefisien $\mathrm{X}_{5}$ bernilai positif sebesar 0,206 nilai tersebut memberikan arti bahwa semakin tinggi relate produk seperti outlet tersebar luas, mereferensikan produk sebagai ciri khas Bogor, pemerintah Bogor mendukung eksistensi, memperhatikan keinginan konsumen, dan informasi produk detail maka akan meningkatkan minat beli terhadap produk berbahan talas.

\section{Pengujian Korelasi Berganda}

Korelasi berganda bertujuan untuk menunjukkan kuatnya hubungan variabel independen secara simultan dengan variabel dependen. Untuk melihat hubungan antara variabel dapat dilihat pada tabel berikut:

Tabel 6. Hasil Perhitungan Korelasi Ganda

\begin{tabular}{|c|c|c|c|c|}
\hline Wode & R & R Square & Adjusted R Squsre & Sto Ero of the Estingte \\
\hline 1 & $810^{4}$ &, 067 & 64 & 1.87739 \\
\hline
\end{tabular}
Model Summary" 
Tabel 6 menunjukkan nilai $\mathrm{R}$ sebesar 0,816 berada diantar nilai interpretasi sebesar 0,8 - 1,00 yang artinya hubungan variabel experiential marketing (sense, feel, think, act dan relate) terhadap variabel minat beli sangat kuat.

\section{Pengujian Koefisien Determinasi}

Koefisien determinasi dilakukan untuk mengetahui besarnya sumbangan persentase pengaruh dari variabel independen (experiential marketing) secara simultan/serentak terhadap variabel dependen (minat beli). Besarnya nilai koefisien determinasi dengan melihat pada nilai R Square sebesar 0,667, artinya minat beli masyarakat $67 \%$ dijelaskan oleh variabel experiential marketing dan $33 \%$ dipengaruhi oleh variabel lain yang tidak diteliti misalnya pelayanan dan fasilitas.

\section{Uji -F}

Uji $F$ dilakukan untuk mengetahui bagaimana pengaruh semua dari variabel independen (variabel $\mathrm{X}$ ) secara bersamasama terhadap variabel dependen $(\mathrm{Y})$.

Hasil rumusannya yaitu apabila $F_{\text {hitung }}$ nilainya lebih kecil atau sama dengan nilai $F_{\text {tabel }}\left(F_{\text {hitung }} \leq F_{\text {tabel }}\right)$ pada $\alpha=0,05$ artinya $\mathrm{H}_{0}$ diterima dan $\mathrm{H}_{\mathrm{a}}$ ditolak dan apabila nilai $F_{\text {hitung }}$ lebih besar nilai dari $F_{\text {tabel }}\left(F_{\text {hitung }}>\right.$ $\left.F_{\text {tabel }}\right)$ pada $\alpha=0,05$ artinya $\mathrm{H}_{0}$ ditolak dan $\mathrm{H}_{\mathrm{a}}$ diterima.

Berdasarkan hasil perhitungan maka diketahui $F_{\text {hitung }}$ adalah:

\section{Tabel 7. Uji F}

ANOVA ${ }^{2}$

\begin{tabular}{|c|c|c|c|c|c|c|}
\hline \multicolumn{2}{|c|}{ Wade } & Sun of Squares & df & Mean Square & $F$ & $5 i g$ \\
\hline 1 & Regression & 602.527 & 5 & 132565 & 37,554 & $.000^{2}$ \\
\hline & Residual & 331,313 & 9 & 3525 & & \\
\hline & Total & 993.840 & 99 & & & \\
\hline
\end{tabular}

Berdasarkan tabel 7 bahwa nilai $F_{h i t u n g}$ sebesar 37,594 yang akan dibandingkan dengan $F_{\text {tabel}}$, untuk mengetahui $F_{\text {tabel }}$ maka perlu perhitungan menggunakan tingkat signifikasi sebesar $0,05(\alpha=5 \%)$ dan $\mathrm{dk}$ (derajat kebebasan) n-k-1 (100-5-1) $=94$. Dengan melihat hasil derajat kebebasan maka didapatkan nilai $F_{\text {tabel }}$ sebesar 2,37 sehingga $F_{\text {hitung }}$ lebih besar dari $F_{\text {tabel }}$ $(37,594>2,37)$ dan memiliki nilai signifikansi $0,000<0,5$ maka $\mathrm{H}_{0}$ ditolak dan $\mathrm{H}_{\mathrm{a}}$ diterima, artinya adalah dimensi (sense, feel, think, act, relate) secara serentak /simultan mempunyai pengaruh positif dan signifikan terhadap minat beli produk UMKM berbahan talas di Bogor.

\section{Uji-t}

Uji-t dilakukan untuk mengetahui adanya pengaruh secara parsial (sebagian dari keseluruhan) variabel independen terhadap variabel dependen, maka dilakukan pengujian rumusan hipotesis menggunakan uji-t dengan tingkat signifikan 0,05 $(\alpha=$ $5 \%$ ). Untuk mengetahui ada/tidak pengaruh dilakukan pengujian data menggunakan SPSS. Berdasarkan tabel 7 diketahui nilai hasil pengujian variabel independen (sense, feel, think, act, relate) terhadap variabel dependen (minat beli), secara parsial variabel independen terhadap dependen adalah :

Tabel 8. Rekapitulasi Hasil Uji-t

\begin{tabular}{|c|c|c|c|c|c|c|}
\hline No & Vanibel & $T_{\text {hitung }}$ & $T_{\text {tibel }}$ & Sigififkan & $\alpha$ & Keterangan \\
\hline 1. & Sense & 1,011 & 1,665 & 0,314 & 0,05 & Tidak Berpenganh \\
\hline 2. & Feel & 2,003 & 1,665 & 0,048 & 0,05 & Berpenganuh \\
\hline 3. & Think & 4,069 & 1,665 & 0,000 & 0,05 & Beppenganuh \\
\hline 4. & Act & 2,664 & 1,665 & 0,009 & 0,05 & Beppenganuh \\
\hline 5. & Relate & 2,001 & 1,665 & 0,048 & 0,05 & Berpenganh \\
\hline
\end{tabular}

Berdasarkan tabel 8 menujukkan dalam hasil perhitungan uji hipotesis terdapat satu variabel yang tidak memiliki pengaruh terhadap minat beli yaitu sense sedangkan variabel feel, think, act, relate memiliki pengaruh terhadap minat beli.

\section{KESIMPULAN DAN IMPLIKASI}

Kesimpulan penelitian adalah;

1. Rata-rata konsumen memiliki tanggapan terhadap variabel sense, feel,think, act 
maupun relate berada pada keriteria penilaian tinggi yaitu :

a) Penilaian konsumen mengenai sense memiliki nilai rata-rata sebesar 3,88

a) Penilaian konsumen mengenai feel memiliki nilai rata-rata sebesar 3,64.

b) Penilaian konsumen mengenai think memiliki nilai rata-rata sebesar 3,82.

c) Penilaian konsumen mengenai act memiliki nilai rata sebesar 3,93.

d) Penilaian konsumen mengenai relate memiliki nilai rata-rata sebesar 3,92

2. Hasil penelitian sense, feel, think, act dan relate secara simultan berpengaruh positif dan signifikan terhadap minat beli.

3. Hasil penelitian secara parsial feel, think, act dan relate berpengaruh terhadap minat beli sedangkan yang tidak memiliki pengaruh terhadap minat beli adalah sense. .

Berdasarkan kesimpulan diatas, untuk meningkatkan minat beli produk UMKM berbahan talas di Bogor maka implikasi yang dapat disampaikan adalah :

1. Indikator pada experiental marketing yang memiliki tanggapan yang berpengaruh dan bernilai tinggi dipertahankan, sedangkan indikator yang berpengaruh namun bernilai rendah ditingkatkan

2. Upaya peningkatan minat beli melalui sense dapat dilakukan dengan melakukan sosialisasi terhadap masyarakat tentang produk ciri khas kota Bogor melalui media sosial maupun secara langsung agar masyarakat Bogor ikut mereferensikan produk berbahan talas sebagai ciri khas Bogor.

3. Upaya peningkatan minat beli melalui feel dilakukan melalui sosialisasi mengenai informasi tentang produk seperti informasi mengenai kandungan gizi, manfaat produk, tanggal kedaluarsa produk, halal dari MUI, izin dari BPOM dan jaminan kesehatan dari Dinas Kesehatan.

4. Upaya peningkatan minat beli melalui think dapat dilakukan dengan melakukan promosi penjualan produk dengan cara menarik melalui pamflet, media sosial, undian, diskon dll.

5. Upaya peningkatan minat beli melalui act dapat dilakukan dengan menampilkan bentuk produk yang unik dan menarik sehingga menarik minat konsumen.

6. Upaya peningkatan minat beli melalui relate dapat dilakukan dengan cara menyediakan outlet produk yang dapat dijangkau oleh konsumen.

\section{UCAPAN TERIMAKASIH}

Ucapan terima kasih kepada masyarakat wilayah kota Bogor, pembeli Produk UMKM berbahan Talas.

\section{DAFTAR PUSTAKA}

Abdurrahman, Herdian, 2015. Manajemen Strategi Pemasaran, Bandung: Pustaka Setia

Alma Buchari, 2011. Manajemen Pemasaran dan Pemasaran Jasa, Bandung: Alfabeta. , 2014. Manajemen Pemasaran dan Pemasaran Jasa. Bandung : Alfabeta

Azwar, Saifuddin, 2007. Sikap Manusia. Teori dan pengukurannya. Edisi ke2. Yogyakarta: Pustaka Pelajar

Ghozali Imam, 2011. Aplikasi Analisis Multivariate dengan program SPSS, Badan Penerbit Universitas Diponegoro, Semarang.

Gujarati, Damodar, 2006. Dasar-Dasar Ekonometrika.Jakarta: Erlangga

Hadi, Sutrisno, 1986. Metodologi Research. Yogyakarta: Andi Offset.

Hendarsono Gersom dan Sugiharto Sugiono, 2013.Analisa Pengaruh Experiential Marketing Kepada minat beliUlang Konsumen Cafe Buntos 99 Sidoarjo, Jurnal Manajemen Pemasaran Vol. 1,No.2, (2013) 1-8, Universitas Kristen Petra, Surabaya. Himademalik Celya, 2011, Pengaruh Sikap Konsumen pada Iklan dan Merek Kepada minat beliKonsumen 
Produk Pasta Gigi Merek Pepsodent (Studi Kasus pada Masyarakat di Kota Bogor), Skripsi Sarjana, Fakultas Ekonomi Universitas Djuanda Bogor

Kertajaya Hermawan. 2006. Marketing In Venus. Jakarta: PT. Gramedia Pustaka Utama

Kotler, Keller. 2012. Marketing Management. New Jersey: Pearson Education.

.2016. Manajemen Pemasaran edisi 12, jilid 1. Jakarta : PT. Indeks

Kotler, Philip and Gray Armstrong. 2009, Prinsip-Prinsip Pemasaran, Edisi 12, jilid 1, Jakarta: Erlangga

Lemeshow, S., David W.H.Jr. (1997). Besar Sampel Dalam Penelitian Kesehatan. Yogyakarta: Gadjahmada University Press.

Margono. 2010. Metodologi Penelitian Pendidikan. Jakarta: Rineka Cipta MediaKom

Priyatno, Duwi 2011, Buku Saku Analisis Statistik Data SPSS, Yogyakarta.

Rendy, Devie, 2013 Analisa Pengaruh Activity Based Costing Terhadap Keunggulan Bersaing Dan Kinerja Organisasi, JURNAL Business Accounting Review, Vol. 1, No. 2, Akuntansi Bisnis Universitas Kristen Petra, Surabaya.

Schiffman, L dan Kanuk Leslie L, 2007 Perilaku Konsumen, Jakarta : PT.Indeks Prestice Hall.

Sugiyono. 2010. Metode Penelitian Kuantitatif Kualitatif dan R\&D. Bandung: Alfabeta. .2013. Metode Penelitian Pendidikan Pendekatan Kuantitatif, Kualitatif, dan R\&D. Bandung: Alfabeta. . 2014. Metode Penelitian

Kuantitatif, Kualitatif, dan Kombinasi (Mixed Methods). Bandung : Alfabeta. 2016. Statistik untuk Penelitian. Bandung: Alfabeta.
Tjiptono Fandy, dan Gregorius Chandra. 2011. Service, Quality and Satisfaction (ed 3). Yogyakarta: Andi

Vinsensius Tetanoe dan Diah Dharmayanti, 2014, Pengaruh Expereintial marketing Terhadap Pembelian Ulang Dengan Kepuasan Pelanggan sebagai Variabel Intervening di Breadtalk Surabaya Town Square, Jurnal Manajemen Pemasaran Vol. 2, No.1, (2014) 1-12, Universitas Kristen Petra, Surabaya

Widarjono, Agus. 2015. Analisis Multivariat dengan Program SPSS, AMOS, dan SMARTPLS. Yogyakarta: UPP STIM YKPN.

Yuningsih Erni, Gemina Dwi, Silaningsih Endang. 2014. Model Pengembangan Wisata Dengan Pendekatan Experiential Marketing Berbasis Kepuasan Konsumen dan Loyalitas Konsumen di Kabupaten Bogor, Laporan Akhir, Universitas Djuanda, Bogor.

\section{Sumber lain:}

Badan Pusat Statistik (BPS) 2016. Komoditas Palawija Kota Bogor 2015.

Dinas Koperasi dan UMKM Kota Bogor 2016

Dinas Kependudukan Dan Pencatatan Sipil 2016.

Peraturan Menteri Dalam Negeri Republik Indonesia Nomor 9 Tahun 2014 (Sumber:

http://bpkad.natunakab.go.id didownload, 25-01-17/10:45)

http://bpkad.natunakab.go.id/attachments/arti cle/75/Permendagri\%209\%20Th\% 202014\%20ttg\%20Pedoman\%20P engembangan $\% 20$ Produk $\% 20$ Ung gulan\%20Lokal.pdfhttp://kotabog or.go.id/index.php/page/detail/17/ produk-nggulan\#.WIhQWvB97IU 